\title{
Social Connections and the Sorting of Workers to Firms*
}

\author{
Marcus Eliason $^{\mathrm{a}, \mathrm{d}}$, Lena Hensvik ${ }^{\mathrm{a}, \mathrm{d}}$, Francis Kramarz ${ }^{\mathrm{b}, \mathrm{c}}$, \\ Oskar Nordström Skans ${ }^{\mathrm{c}, \mathrm{d}, \mathrm{a}}$ \\ ${ }^{a}$ Institute for Labour Market and Education Policy Evaluation (IFAU), Sweden; \\ ${ }^{\mathrm{b}}$ CREST, France; \\ ${ }^{\mathrm{c}}$ Department of Economics, Uppsala University, Sweden; \\ ${ }^{\mathrm{d}}$ Uppsala Center for Labor Studies (UCLS), Sweden
}




\section{Motivation}

- Networks are deemed important in matching workers and firms

- Networks are often presumed to increase inequality, since "birds of a feather flock together"

- Theoretical contributions on networks' role share this view (Montgomery, 1991 or Calvo-Armengol and Jackson, 2004)

- Indeed, sorting has been shown in recent contributions (Card various ref.) to increase inequality: high-wage workers tend to go to highwage firms

- Networks should only reinforce this phenomenon ("sorting increases inequality") because social ties are unequally distributed 


\section{What we do}

- We assess the impact of social connections on the sorting of workers to firms (and the presumption that connections increase sorting inequality)

- We first examine the distribution of displaced workers' social connections to employed workers and their firms

- Using Swedish data, we measure multiple types of networks, of both the strong and weak sort (family, former co-worker, former classmate, current neighbor)

- We estimate an AKM decomposition (to assess sorting inequality)

- Then, we examine the causal impact of connections on hiring for these displaced workers and how connections and their strength affect sorting inequality

- Finally, we look at how connections affect sorting for all job-to-job movers 


\section{What we find}

- Our measured social connections indeed display homophily: positive sorting in terms of earnings capacity; high-wage workers are connected to high-wage workers who tend to be employed by high-wage firms

- This finding is most pronounced for former co-worker ties and classmates from university

- Social connections matter when looking for jobs

- a worker is much more likely (one order of magnitude) to find a job in the exact establishment where she has a connection than someone from the same displacement event with no such connection

- Family (strong ties) and past co-workers matter most

- Immune to common preferences of the worker and her connection for a specific firm (repeated displacements and other evidence) 


\section{What we find}

- The magnitude of these effects is the same for low-wage and highwage workers

- The magnitude of these effects is much larger when the connection is to a low-wage employer rather than to a high-wage employer, regardless of the high-wage/low-wage status of the connected worker

- The resulting outcome is that sorting inequality for matches formed through connections is lower than that due to "unconnected" market matches

- This result also holds not only for the displaced but also for all job-tojob movers 


\section{Empirical strategy}

Our explanatory ("treatment") variable of interest is the indicator $C_{i j k(l)}$, which equals one if there is a social connection between worker $i$, employed in establishment $j$, and an "intermediary" worker $l$ employed in establishment $k(l)$, and zero otherwise. In the paper, $C_{i j k(l)}$ takes the value one if $i$ and $l$ belong to the same family, have worked together in the past, are former classmates, or are neighbors with children of the same age.

Most of our focus is on the causal analysis. To assess whether having a connection $C$ to a specific establishment causes an increase in the probability of moving to that establishment, we use displacement events. Indeed, mobility requires that a worker $i$ chooses to search for and accept a new job in order for her to leave establishment $j$. To avoid conditioning on those choosing to relocate when offered a job, we focus on mobility decisions due to external factors and therefore rely on job displacements at the time of establishment closures. 


\section{Empirical strategy}

Our key outcome is $H_{i j k}$, which equals one if worker $i$ (from closing establishment $j$ ) is hired by establishment $k$, and zero otherwise. ${ }^{11}$ Because of displacements, staying in the closing establishment $j$ is not an option and it is sufficient to concentrate on the probability that establishment $k$ hire worker $i$ (from $j$ ) as a function of social connections between $k$ and $i$.

Using potential outcomes notation, we let $H_{i j k}^{0}$ equal one if $i$ would be hired by $k$ in absence of connection to $k$. Correspondingly, $H_{i j k}^{1}$ equals one if $i$ would be hired by $k$ in presence of a connection to $k$. The causal effect of interest is the difference between the two, i.e. $\gamma_{i j k}=H_{i j k}^{1}-H_{i j k}^{0}$. Thus, the observed outcome is

$$
H_{i j k}=H_{i j k}^{0}+\gamma_{i j k} C_{i j k}
$$

- The causal parameter $\gamma$ captures all aspects that crucially rely on the existence of a current social connection at the time of displacement.

- The non-connected hiring outcome $H_{i j k}^{0}$, on the other hand, encompasses all aspects that are relevant for whether or not displaced worker $i$ is hired by establishment $k$ in the absence of a social connection between the two. 


\section{Empirical strategy}

To identify the causal parameter $\gamma$, we need to account for any systematic relationship between social connections $\left(C_{i j k}\right)$ and the potential that connected employers would have hired the very same (connected) workers through the "market", had the connections not been there (i.e. $H_{i j k}^{0} \mid C_{i j k}=1$ ). ${ }^{13}$ Identification through conditioning on observables is feasible if there exists a set of fixed-effects $\alpha$ and a vector of observable factors $X_{i k}$ such that $H_{i j k}^{0}=\alpha+X_{i k} \beta+\varepsilon_{i j k}$ and $\varepsilon_{i j k} \perp C_{i j k}$, i.e. if the potential for a "market" hire is independent of the presence of a social connection, conditional on fixed-effects and observable factors. For the remainder of the paper, we maintain the $\varepsilon_{i j k} \perp C_{i j k}$ assumption under various fixed effects configurations.

Our main identification strategy relies on a fixed-effect $\alpha_{j k}$ for each pair of closing establishment ( $j$ ) and potential hiring establishment ( $k$ ). Using the dyadic data described above, we estimate the following model:

$$
H_{i j k}=\alpha_{j k}+X_{i k} \beta+\gamma C_{i j k}+\varepsilon_{i j k}
$$

where the establishment-pair fixed-effects $\left(\alpha_{j k}\right)$ account for all shared aspects (including, e.g., location, industry, and types of firm-specific human capital) that relate the closing establishment ( $j$ ) and the potential hiring establishment $(k)$ to each other. 


\section{Robustness}

Specificity: If we replace the actual connected establishment $k$ by other very similar ("placebo") establishment $k^{\prime}$, the effects shrink towards zero. We use two different types of placebos: $i$ ) other, randomly selected, establishment within the same location and industry and ii) other establishment within the same location and firm.

Robustness to time-invariant individual preferences for specific establishments: We exploit timevariation in workers' social networks between displacement events for the small sample of workers who are displaced multiple times.

The role of social proximity: Our data allow us to construct measures that proxy for social proximity, or "tie strength", of a given social relationship. 


\section{Sorting inequality}

It is straightforward to adapt the framework of equation (1) to a study of sorting inequality in the spirit of Card et al. (2013). To this end, we first need to estimate the AKM model of Abowd et al. (1999):

$$
\ln w_{i t}=\theta_{i}+\psi_{k(i, t)}+X_{i t} \beta+\varepsilon_{i t},
$$

where $w_{i t}$ is worker $i$ 's wage in year $t, \theta_{i}$ is a person fixed-effect for worker $i$, and $\psi_{k(i, t)}$ is an establishment ( $k$ ) fixed-effect in year $t . X_{i t} \beta$ is a vector of control variables, which as in Card et al. (2013), includes an unrestricted set of year indicators, and education level interacted with age in quadratic and cubic terms. ${ }^{16}$

$\operatorname{Corr}\left(\theta_{i}, \theta_{l} \mid C_{i l}=1\right)>0$, will be interpreted as baseline homophily.

$\operatorname{Corr}\left(\theta_{i}, \psi_{k} \mid C_{i k}=1\right)$.

$$
H_{i j k}=\alpha_{j k}+X_{i k} \beta+\gamma\left(\theta_{i}, \psi_{k}\right) C_{i j k}+\varepsilon_{i j k},
$$

where we assume that $\gamma\left(\theta_{i}, \psi_{k}\right)$ is a second-order polynomial:

$$
\gamma\left(\theta_{i}, \psi_{k}\right)=\gamma_{1} \theta_{i}+\gamma_{2} \theta_{i}^{2}+\gamma_{3} \theta_{i} \psi_{k}+\gamma_{4} \psi_{k}+\gamma_{5} \psi_{k}^{2}
$$




\section{Within-worker identification}

Let us first define $K_{i j k}$ as the set of establishments $k$ that displaced worker $i$ (from $j$ ), is connected to (i.e., define $K_{i j k}: k \in K_{i j k}$ iff $C_{i j k}=1$ ). To identify the relative importance of the various types of connections or agents within this set, we define a fixed-effect $\phi_{K_{i j k}}$ for each $K_{i j k}$ set. $^{19}$

Thus, focusing on heterogeneity in terms of agents (not connections) for reasons of brevity, we can rewrite equation (4) as:

$$
H_{i j k}=\phi_{K_{i j k}}+X_{i k} \beta+\gamma^{I}\left(\theta_{i}, \psi_{k}\right) C_{i j k}+\varepsilon_{i j k}
$$

where, as in (4), $\gamma^{I}$ represents a second-order polynomial and $X_{i k}$ contain the components of the same polynomial. ${ }^{20}$ Because the new fixed effect requires the existence of a social connection between worker $i$ and establishment $k$, some components of these polynomials are in practice absorbed. ${ }^{21}$ Thus, equation (5) reduces to:

$$
\gamma^{I}\left(\theta_{i}, \psi_{k}\right)=\gamma_{3}^{I} \theta_{i} \psi_{k}+\gamma_{4}^{I} \psi_{k}+\gamma_{5}^{I} \psi_{k}^{2}
$$

where the parameters are numbered as in equation (5) and the estimate of $\gamma_{3}^{n, I}$ thus identifies the contribution of causal effects to sorting. 


\section{Data}

Table 1: The number of potentially hiring establishments ( $k$ ) (per displaced worker $(i)$ and in total) connected to displaced worker $(i)$, by type of social connection

\begin{tabular}{lrrrrr}
\hline & \multicolumn{3}{c}{ Type of social connection } \\
\cline { 2 - 6 } & $\begin{array}{r}\text { Family } \\
\text { member }\end{array}$ & $\begin{array}{r}\text { Former } \\
\text { co-worker }\end{array}$ & $\begin{array}{r}\text { Former } \\
\text { classmate }\end{array}$ & $\begin{array}{r}\text { Current } \\
\text { neighbor }\end{array}$ & $\begin{array}{r}\text { Any } \\
\text { connection }\end{array}$ \\
\hline Per displaced worker $(i)$ & 1.17 & 2.59 & 3.52 & 1.63 & 8.82 \\
In total & 338,518 & 749,370 & $1,019,027$ & 471,032 & $2,553,066$ \\
\hline
\end{tabular}

Note: The Table gives the number of connections for displaced workers within the used sample (1990-2006). 


\section{Data}

Table 2: Description of the AKM samples

\begin{tabular}{lrrrrr}
\hline & \multicolumn{3}{c}{} & \multicolumn{2}{c}{ Estimation sample } \\
\cline { 2 - 6 } & $\begin{array}{r}\text { AKM } \\
\text { estimation } \\
\text { sample }\end{array}$ & $\begin{array}{r}\text { All } \\
\text { job-to-job } \\
\text { hires }\end{array}$ & $\begin{array}{r}\text { Connected } \\
\text { job-to-job } \\
\text { hires }\end{array}$ & $\begin{array}{r}\text { Displaced } \\
\text { hires }\end{array}$ & $\begin{array}{r}\text { Displaced } \\
\text { connected } \\
\text { hires }\end{array}$ \\
\hline Number of person effects & $5,785,081$ & $3,315,423$ & 424,789 & 83,537 & 10,202 \\
Number of establishment effects & 829,111 & 276,298 & 119,377 & 43,469 & 7,127 \\
Mean of person effects & 0.000 & -0.104 & -0.101 & -0.117 & -0.111 \\
Mean of establishment effects & 4.502 & 4.525 & 4.525 & 4.507 & 4.503 \\
Std dev. of person effects & 0.270 & 0.269 & 0.255 & 0.250 & 0.245 \\
Std dev. of establishment effects & 0.126 & 0.154 & 0.152 & 0.155 & 0.152 \\
Correlation person/establishment effect & 0.038 & 0.129 & 0.083 & 0.089 & 0.049 \\
Mean of log wages & 9.664 & - & - & - & - \\
Std dev. of log wages & 0.466 & - & - & - & - \\
\hline No of observations & $62,002,038$ & $3,315,521$ & 424,792 & 83,540 & 10,202 \\
\hline
\end{tabular}

Note: Column (1) presents summary statistics for AKM person and establishment effects in the full sample of workers and establishments during 1985-2009. In columns (2)-(5) we present statistics for our observation period of interest 1995-2006.

When focusing on transitions in columns (2)-(5), we use the AKM person effects estimated in the pre-transition period. Displaced workers are defined in Section 3.2. Connected hires include the four broad types of social connections (family members, former co-workers, former classmates and current neighbors) defined in Section 3.3. 
Table 3: Summary statistics for the displaced and intermediary workers and for the estimation sample comprised by dyads of potential hiring establishments $k$ and displaced workers $i$

\section{Data}

\begin{tabular}{|c|c|c|c|c|c|c|}
\hline & \multicolumn{2}{|c|}{$\begin{array}{r}\text { Displaced } \\
\text { workers }(i)\end{array}$} & \multicolumn{2}{|c|}{$\begin{array}{r}\text { Intermediary } \\
\text { workers }(l)\end{array}$} & \multicolumn{2}{|c|}{$\begin{array}{r}\text { Dyads of displaced } \\
\text { workers } i \text { and } \\
\text { potential hiring } \\
\text { establishments } k\end{array}$} \\
\hline & $N$ & $\%$ & $N$ & $\%$ & $N$ & $\%$ \\
\hline \multicolumn{7}{|l|}{ Sex } \\
\hline Female & 113,738 & 39.31 & 853,104 & 37.87 & $24,119,673$ & 58.67 \\
\hline Male & 175,594 & 60.69 & $1,399,683$ & 62.13 & $16,992,101$ & 41.33 \\
\hline \multicolumn{7}{|l|}{ Nativity } \\
\hline Swedish born & 257,686 & 89.06 & $2,095,419$ & 93.01 & $37,292,005$ & 90.71 \\
\hline Foreign born & 31,646 & 10.94 & 157,548 & 6.99 & $3,819,769$ & 9.29 \\
\hline \multicolumn{7}{|l|}{ Age } \\
\hline $20-34$ years & 149,529 & 51.68 & $1,379,492$ & 61.23 & $25,565,797$ & 62.19 \\
\hline $35-49$ years & 88,075 & 30.44 & 629,184 & 27.93 & $10,461,203$ & 25.45 \\
\hline 50-64 years & 51,728 & 17.88 & 244,291 & 10.84 & $5,084,770$ & 12.37 \\
\hline \multicolumn{7}{|l|}{ Attained education } \\
\hline Compulsory school & 69,044 & 23.86 & 312,826 & 13.89 & $6,538,236$ & 15.90 \\
\hline High school & 163,735 & 56.59 & $1,374,302$ & 61.00 & $24,250,767$ & 58.99 \\
\hline College/university & 54,829 & 18.95 & 561,351 & 24.92 & $10,199,868$ & 24.81 \\
\hline \multicolumn{7}{|l|}{ Employment in $t+1$} \\
\hline Any employment & 211,282 & 73.02 & $2,252,967$ & 100.00 & $33,921,201$ & 82.51 \\
\hline In connected establishment & 9,143 & 3.16 & $2,252,967$ & 100.00 & 17,707 & 0.04 \\
\hline \multicolumn{7}{|l|}{ AKM person effects $^{a}$} \\
\hline Low & 78,098 & 26.99 & $1,003,740$ & 44.55 & $11,711,626$ & 28.49 \\
\hline Medium & 65,505 & 22.64 & 733,727 & 32.57 & $8,495,645$ & 20.66 \\
\hline High & 46,444 & 16.05 & 445,638 & 19.78 & $4,756,028$ & 11.57 \\
\hline N/A & 99,285 & 34.32 & 69,862 & 3.10 & $16,148,479$ & 39.28 \\
\hline \multicolumn{7}{|l|}{ AKM establishment effects ${ }^{a}$} \\
\hline Low & 102,714 & 35.50 & 509,163 & 22.60 & & \\
\hline Medium & 88,522 & 30.60 & 795,413 & 35.31 & & \\
\hline High & 74,460 & 25.74 & 916,296 & 40.67 & & \\
\hline N/A & 23,636 & 8.17 & 32,095 & 1.42 & & \\
\hline No of observations & \multicolumn{2}{|r|}{289,332} & \multicolumn{2}{|c|}{$2,252,967$} & \multicolumn{2}{|c|}{$41,111,774$} \\
\hline
\end{tabular}




\section{Results}

Table 4: Correlations between the AKM person effect of the displaced worker and the person and establishment of their connections using raw (non-residualized) and residualized person effects

\begin{tabular}{|c|c|c|c|c|c|}
\hline & \multicolumn{2}{|c|}{$\operatorname{Corr}\left(\theta_{i}, \theta_{l} \mid C_{i l}=1\right)$} & \multicolumn{2}{|c|}{$\operatorname{Corr}\left(\theta_{i}, \psi_{k} \mid C_{i k(l)}=1\right)$} & \multirow[b]{2}{*}{$N$} \\
\hline & $\begin{array}{r}\text { Raw } \\
\text { person effects }\end{array}$ & $\begin{array}{l}\text { Residualized } \\
\text { person effects }\end{array}$ & $\begin{array}{r}\text { Raw } \\
\text { person effects }\end{array}$ & $\begin{array}{r}\text { Residualized } \\
\text { person effects }\end{array}$ & \\
\hline $\begin{array}{l}\text { Panel A: } \\
\text { Any connection }\end{array}$ & 0.164 & 0.071 & 0.061 & 0.008 & $1,597,994$ \\
\hline $\begin{array}{l}\text { Panel B: } \\
\text { Family member } \\
\text { Former co-worker } \\
\text { Former classmate } \\
\text { Current neighbor }\end{array}$ & $\begin{array}{l}0.042 \\
0.185 \\
0.201 \\
0.073\end{array}$ & $\begin{array}{l}0.057 \\
0.098 \\
0.055 \\
0.053\end{array}$ & $\begin{array}{l}0.027 \\
0.097 \\
0.084 \\
0.026\end{array}$ & $\begin{array}{r}0.017 \\
0.062 \\
-0.030 \\
0.018\end{array}$ & $\begin{array}{l}195,099 \\
501,706 \\
587,511 \\
304,678\end{array}$ \\
\hline $\begin{array}{l}\text { Panel C: } \\
\text { Family member }\end{array}$ & & & & & \\
\hline $\begin{array}{l}\text { Parent } \\
\text { Adult child } \\
\text { Spouse } \\
\text { Sibling }\end{array}$ & $\begin{array}{r}0.052 \\
0.101 \\
-0.134 \\
0.159\end{array}$ & $\begin{array}{l}0.031 \\
0.046 \\
0.050 \\
0.072\end{array}$ & $\begin{array}{r}-0.017 \\
0.086 \\
0.032 \\
0.019\end{array}$ & $\begin{array}{r}-0.013 \\
0.066 \\
0.029 \\
0.009\end{array}$ & $\begin{array}{r}37,477 \\
27,265 \\
25,614 \\
104,743\end{array}$ \\
\hline $\begin{array}{l}\text { Former classmate } \\
\text { High school }\end{array}$ & 0.099 & 0.047 & 0.024 & -0.033 & 509,471 \\
\hline College/university & 0.289 & 0.098 & 0.137 & 0.013 & 78,040 \\
\hline
\end{tabular}

Note: Column (1) shows the correlation between the AKM person effect of displaced worker $(i)$ and the person effects of the intermediary workers $l$ to whom they are sociall connected. In column (2) we show the relationship when both these person effects have been residualized from age at displacement, education level and gender. Column (3) shows the correlation between the AKM person effect of displaced worker $i$ and the AKM establishment effects of connected establishments $k$. In column (4) we have residualized the AKM person effect of the displaced worker $(i)$ from age at displacement, education level and gender. 
(a) Non-residualized AKM effects: Displaced workers by intermediary workers (col. [1] of Table 4, Panel B)

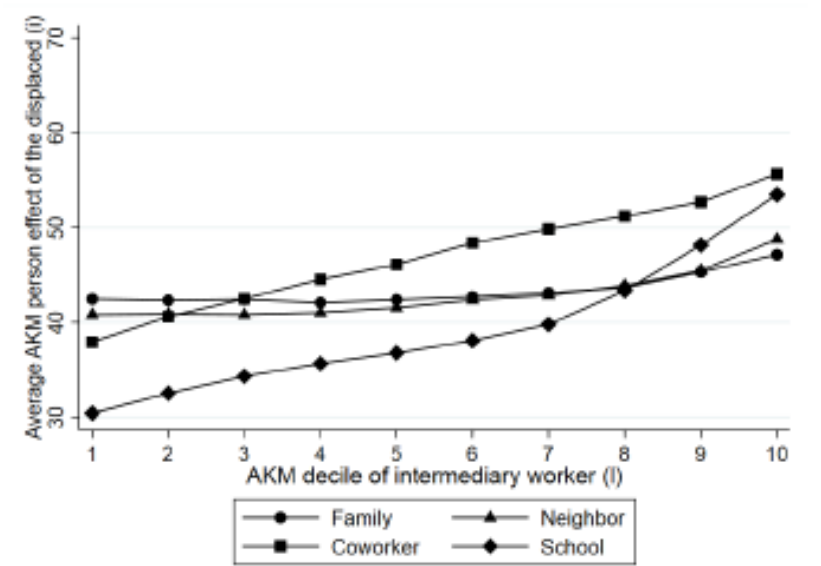

(c) Non-residualized AKM effects: Displaced workers by potential hiring establishments (col. [3] of Table 4, Panel B)

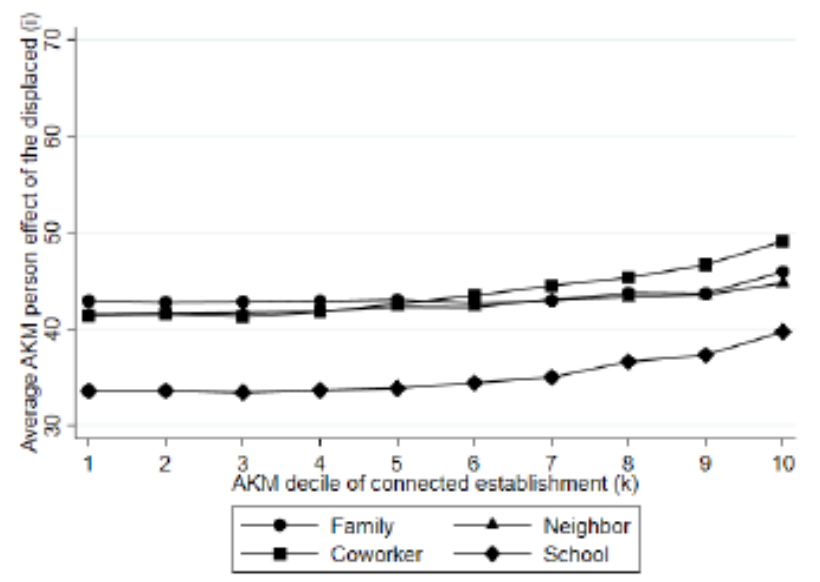

Figure 1: Average percentile of displaced workers' non-residualized and residualized AKM effects $(\theta$ and $\hat{\theta}_{i}$, respectively) by decile of intermediary workers' and the potential hiring establishments' AKM effects $\left(\theta_{l} \mid C_{i l}=1\right.$ and $\hat{\theta}_{l} \mid C_{i l}=1$, respectively) for each type of social connection. ntermediary workers (col. [2] of Table 4, Panel B)

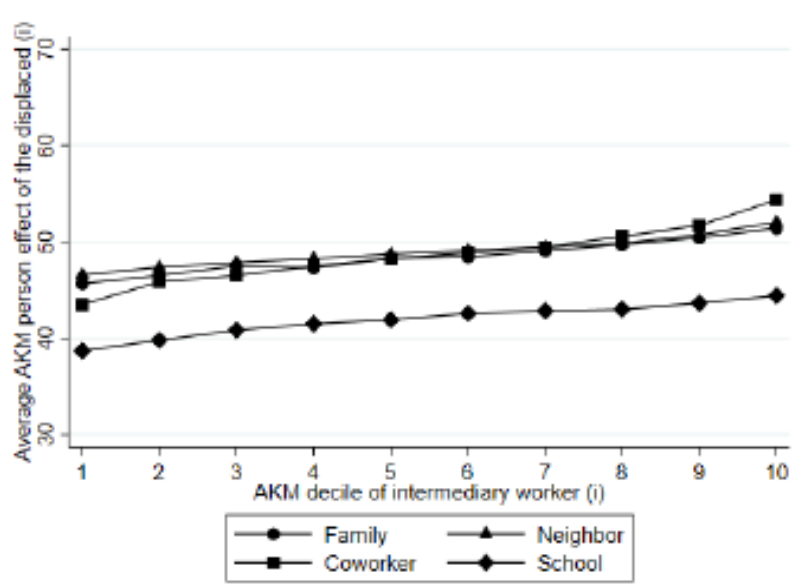

(d) Residualized AKM effects: Displaced workers by potential hiring establishments (col. [4] of Table 4 Panel B)

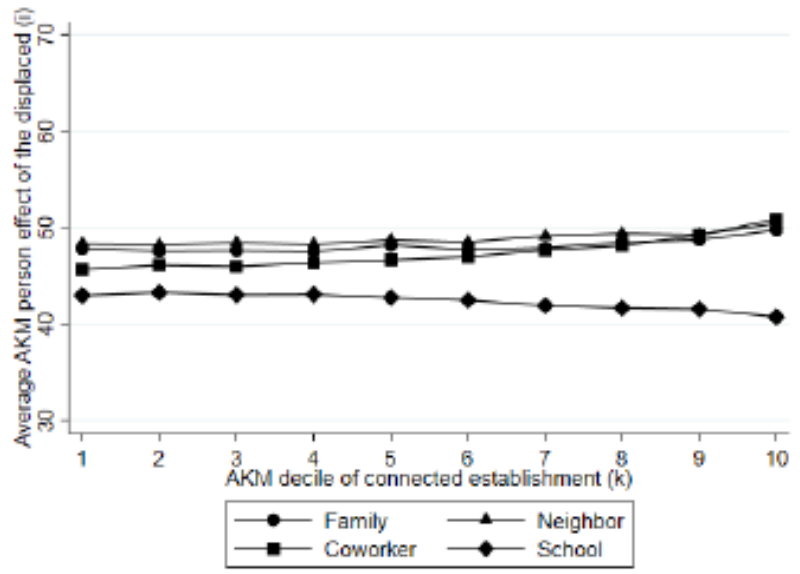



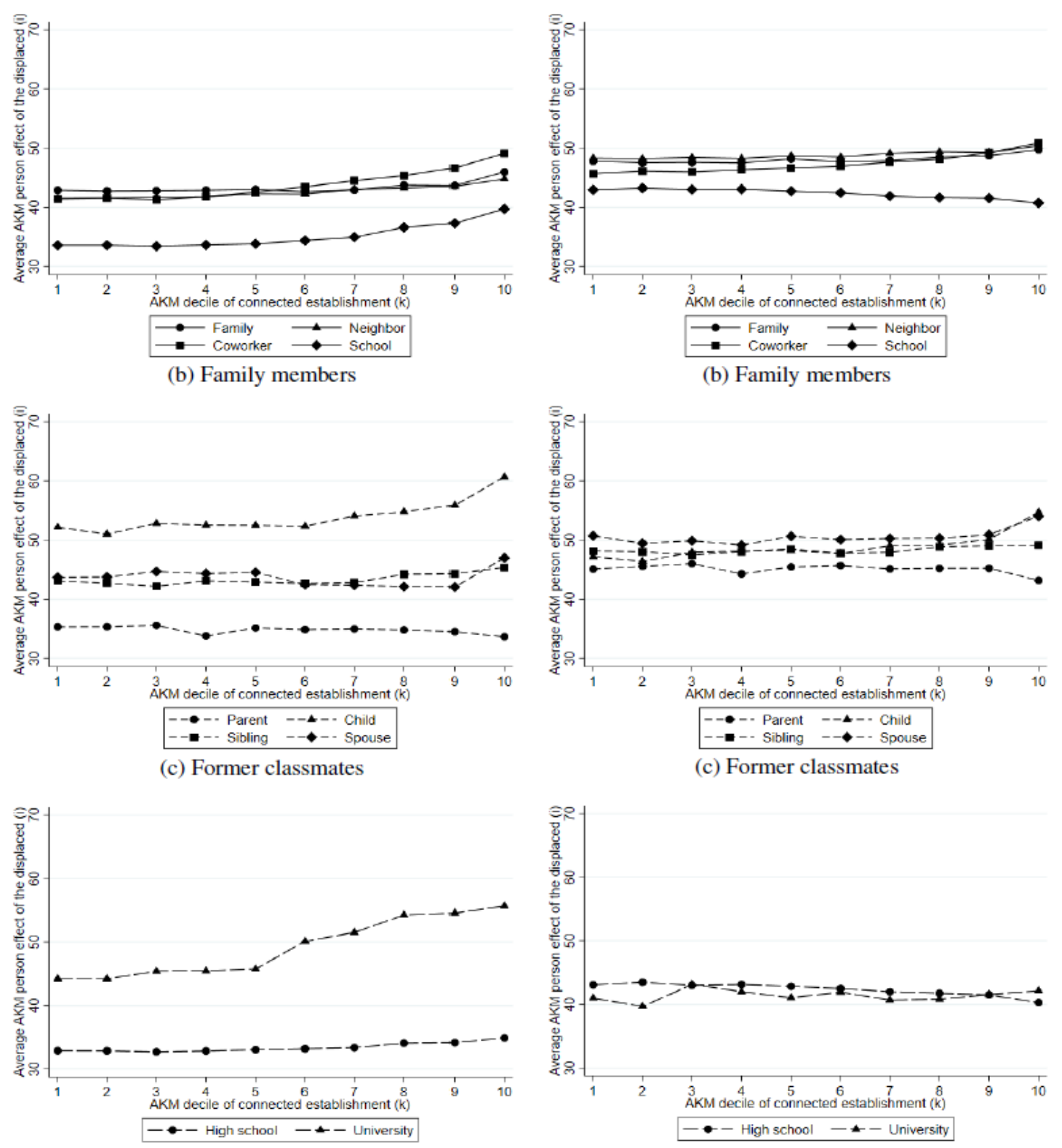

Figure 3: Mean person effects $\left(\theta_{i}\right)$ percentile of Figure 4: Mean residualized person effects $\left(\hat{\theta}_{i}\right)$ perdisplaced workers (y-axis) by decile of establish- centile of displaced workers (y-axis) by decile of ments effects of connected establishments $\left(\psi_{k} \mid\right.$ establishments effects $\left(\psi_{k} \mid C_{i k}=1\right)$ of connected $C_{i k}=1$ ). establishments. 
Table 5: Estimated effects of social connections by type of connection, with alternative fixed-effects

\begin{tabular}{|c|c|c|c|c|c|c|}
\hline & \multicolumn{2}{|c|}{$\begin{array}{r}\text { "Baseline" } \\
\text { ( } j k \text {-fixed-effects) }\end{array}$} & \multicolumn{2}{|c|}{$\begin{array}{r}\text { "Multiple } \\
\text { displacements" } \\
\text { (ik-fixed-effects) }\end{array}$} & \multicolumn{2}{|c|}{$\begin{array}{c}\text { "Within-worker } \\
\text { identification" } \\
\text { ( } K_{i j k} \text {-fixed-effects) }\end{array}$} \\
\hline & Coef. & (s.e.) & Coef. & (s.e.) & Coef. & (s.e.) \\
\hline \multicolumn{7}{|l|}{ Panel A: } \\
\hline Any connection & 0.270 & $(0.005)$ & 0.305 & $(0.025)$ & \multirow[t]{2}{*}{ N/A } & \\
\hline Constant & 0.026 & $(0.000)$ & 0.085 & $(0.012)$ & & \\
\hline \multicolumn{7}{|l|}{ Panel B: } \\
\hline Family member & 1.095 & $(0.020)$ & 1.196 & $(0.173)$ & 1.464 & $(0.036)$ \\
\hline Former co-worker & 0.253 & $(0.010)$ & 0.477 & $(0.048)$ & 0.714 & $(0.030)$ \\
\hline Former classmate & 0.066 & $(0.004)$ & 0.101 & $(0.025)$ & 0.157 & $(0.026)$ \\
\hline Current neighbor & 0.086 & $(0.008)$ & 0.040 & $(0.033)$ & & \\
\hline Constant & 0.027 & $(0.000)$ & 0.075 & $(0.013)$ & 0.014 & $(0.002)$ \\
\hline \multicolumn{7}{|l|}{ Panel C: } \\
\hline \multicolumn{7}{|l|}{ Family members } \\
\hline Parent & 1.867 & $(0.052)$ & 1.692 & $(0.440)$ & 2.061 & $(0.058)$ \\
\hline Adult child & 0.667 & $(0.051)$ & 0.797 & $(0.357)$ & 1.388 & $(0.065)$ \\
\hline Spouse & 1.971 & $(0.078)$ & 2.683 & $(0.741)$ & 2.526 & $(0.081)$ \\
\hline Sibling & 0.696 & $(0.023)$ & 0.832 & $(0.195)$ & 1.105 & $(0.042)$ \\
\hline \multicolumn{7}{|l|}{ Former co-worker } \\
\hline $1-20$ & 0.527 & $(0.029)$ & 0.960 & $(0.124)$ & 1.164 & $(0.045)$ \\
\hline $21-50$ & 0.217 & $(0.018)$ & 0.378 & $(0.073)$ & 0.664 & $(0.040)$ \\
\hline $51-100$ & 0.140 & $(0.014)$ & 0.224 & $(0.060)$ & 0.545 & $(0.038)$ \\
\hline \multicolumn{7}{|l|}{ Former classmate } \\
\hline High school & 0.064 & $(0.004)$ & 0.094 & $(0.025)$ & 0.231 & $(0.027)$ \\
\hline College/university & 0.088 & $(0.018)$ & 0.195 & $(0.117)$ & 0.464 & $(0.043)$ \\
\hline \multicolumn{7}{|l|}{ Current neighbor } \\
\hline $1-20$ & 0.072 & $(0.072)$ & 0.154 & $(0.428)$ & & \\
\hline $21-50$ & 0.084 & $(0.021)$ & 0.025 & $(0.087)$ & & \\
\hline $51-100$ & 0.079 & $(0.009)$ & 0.037 & $(0.035)$ & & \\
\hline Constant & 0.026 & $(0.000)$ & 0.073 & $(0.013)$ & 0.010 & $(0.002)$ \\
\hline No of fixed-effects & \multicolumn{2}{|c|}{$2,087,560$} & \multirow{2}{*}{\multicolumn{2}{|c|}{$\begin{array}{l}147,996 \\
295,992\end{array}$}} & \multirow{2}{*}{\multicolumn{2}{|c|}{$\begin{array}{r}548,820 \\
41,111,774\end{array}$}} \\
\hline No of observations & & 111,774 & & & & \\
\hline
\end{tabular}

Note: Data are in dyadic form with one observation per combination of displaced worker and potential hiring establishment.

All estimates are expressed in percentage points, i.e., the coefficients are multiplied by 100 . Baseline model uses a fixed-effect for each pair of closing and potential hiring establishments. Since establishments only close once, these fixed-effects are yearspecific by construction. Alternative model for workers with multiple displacements uses fixed-effect for each combination of individual and connected establishment, thus exploiting variation in network structure between displacements. Since establishments only close once, these fixed-effects are year-specific by construction. Within-worker identification uses fixed-effect for each combination of individual, set of connected establishments, and displacement year as discussed in Section 2.3.1 Standard errors are clustered on the potential hiring establishment-and-year level. 


\section{Results}

Table 6: Placebo tests based on other non-connected potential hiring establishments

\begin{tabular}{|c|c|c|c|c|c|c|}
\hline & \multicolumn{2}{|c|}{ Baseline $^{a}$} & \multicolumn{2}{|c|}{${\text { Placebo } I^{b}}^{b}$} & \multicolumn{2}{|c|}{ Placebo II ${ }^{c}$} \\
\hline & Coef. & (s.e.) & Coef. & (s.e.) & Coef. & (s.e.) \\
\hline \multicolumn{7}{|l|}{ Panel A: } \\
\hline Any connection & 0.270 & $(0.005)$ & 0.029 & $(0.004)$ & 0.014 & $(0.001)$ \\
\hline Constant & 0.026 & $(0.000)$ & 0.006 & $(0.001)$ & 0.006 & $(0.000)$ \\
\hline \multicolumn{7}{|l|}{ Panel B: } \\
\hline Family member & 1.095 & $(0.020)$ & 0.037 & $(0.011)$ & 0.016 & $(0.004)$ \\
\hline Former co-worker & 0.253 & $(0.010)$ & 0.075 & $(0.012)$ & 0.016 & $(0.003)$ \\
\hline Former classmate & 0.066 & $(0.004)$ & 0.011 & $(0.004)$ & 0.010 & $(0.002)$ \\
\hline Current neighbor & 0.086 & $(0.008)$ & 0.015 & $(0.009)$ & 0.023 & $(0.006)$ \\
\hline Constant & 0.027 & $(0.000)$ & 0.006 & $(0.001)$ & 0.006 & $(0.000)$ \\
\hline No of fixed-effects & \multicolumn{2}{|c|}{$2,087,560$} & \multicolumn{2}{|r|}{391.438} & \multicolumn{2}{|c|}{$1,540,941$} \\
\hline No of observations & \multicolumn{2}{|c|}{$41,111,774$} & \multicolumn{2}{|c|}{$3,676,175$} & \multicolumn{2}{|c|}{$29,891,982$} \\
\hline
\end{tabular}

Notes: Data are in dyadic form with one observation per combination of displaced worker and potential hiring establishment. All estimates are expressed in percentage points, i.e., the coefficients are multiplied by 100. All estimations include establishment-pair(-and-year) fixed-effects. Standard errors are clustered on the potential hiring establishment-and-year level.

${ }^{a}$ Repeats the first column of Table 5.

${ }^{b}$ Each potential hiring establishment has been replaced by another randomly selected establishment within the same firm, location (i.e., municipality), and industry (i.e., 3-digit code).

${ }^{c}$ Each potential hiring establishment has been replaced by another randomly selected establishment within the same location (i.e., municipality) and industry (i.e., 3-digit code). 


\section{Results}

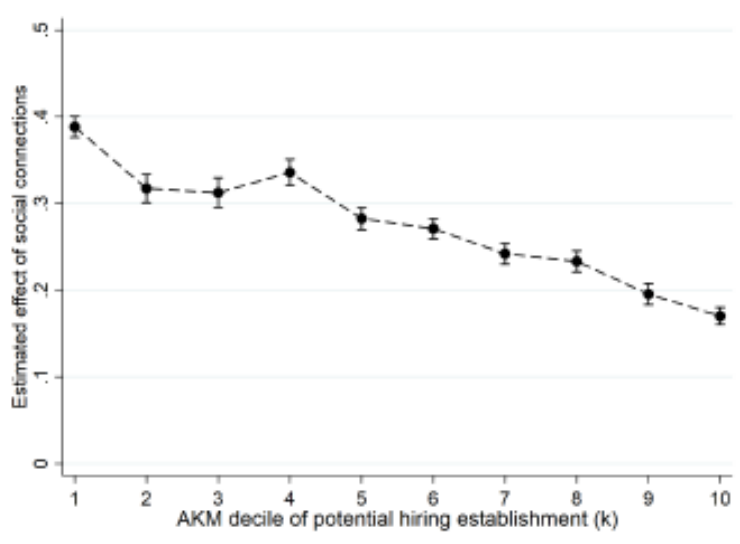

Figure 2: Estimated effects of any social connection by deciles potential hiring establishments' AKM effects (i.e. $\psi_{k}$ )

Notes: The figure shows interactions with AKM deciles of potential hiring establishment $(k)$ using the baseline model with $j, k$-fixed-effects. All estimates are expressed in percentage points.

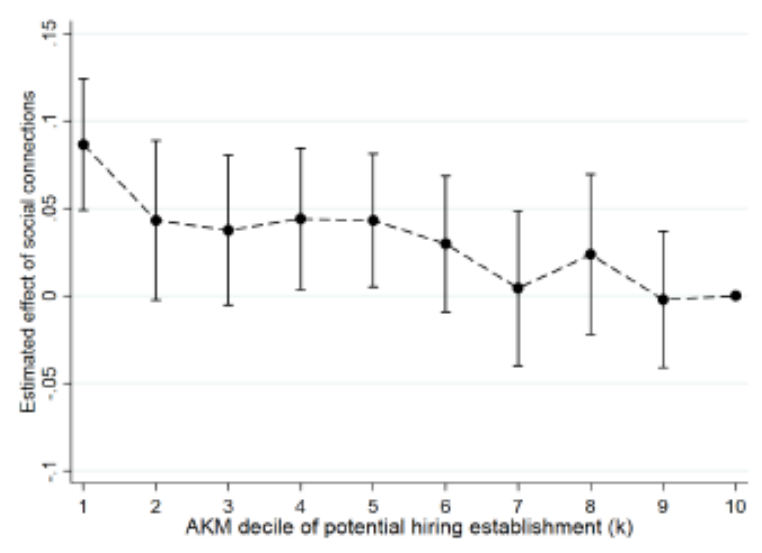

Figure 3: Within-worker identification estimates by AKM decile of potential hiring establishment $\left(\psi_{k}\right)$ Notes: The figure is based on the model of equation (6), which includes worker and set of connected establishments and year fixed-effects. It shows the interactions with AKM deciles of potential hiring establishment. Decile 10 is the reference category. All estimates are expressed in percentage points. 


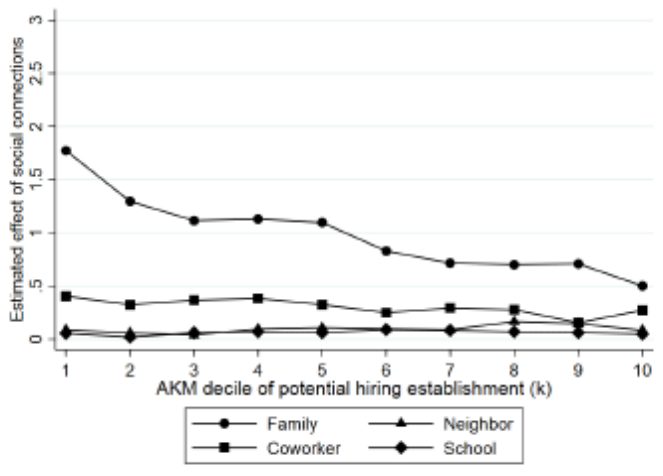

Figure 4: Estimated effect of each type of social connection by decile of the displaced potential hiring establishments' AKM effects (i.e. deciles of $\psi_{k}$ ).

Note: The figure shows interactions with AKM deciles of potential hiring establishment $(k)$ using the baseline model with $j, k$-fixed-effects. For coefficients and standard errors of corresponding estimated linear slopes, see Table B.3 in the Appendix.

All estimates are expressed in percentage points.

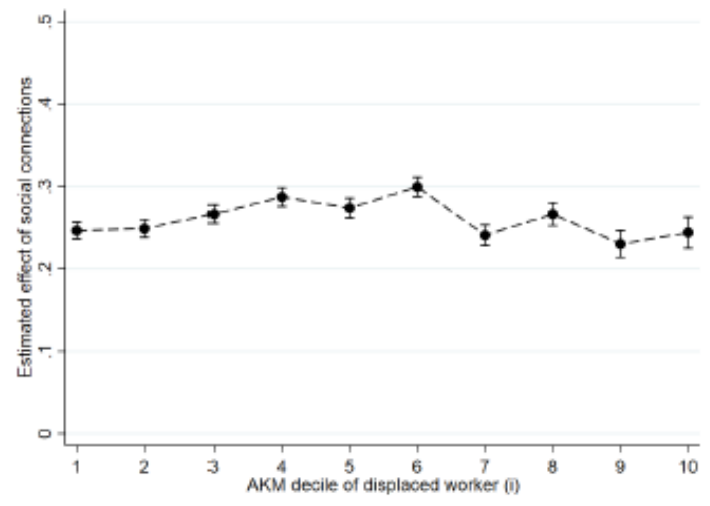

Figure 5: Estimated effects of any social connection by deciles of the displaced workers' AKM effects (i.e. $\theta_{i}$ )

Notes: The figure shows interactions with AKM deciles of displaced worker $(i)$ using the baseline model with $j, k$-fixed-effects All estimates are expressed in percentage points.

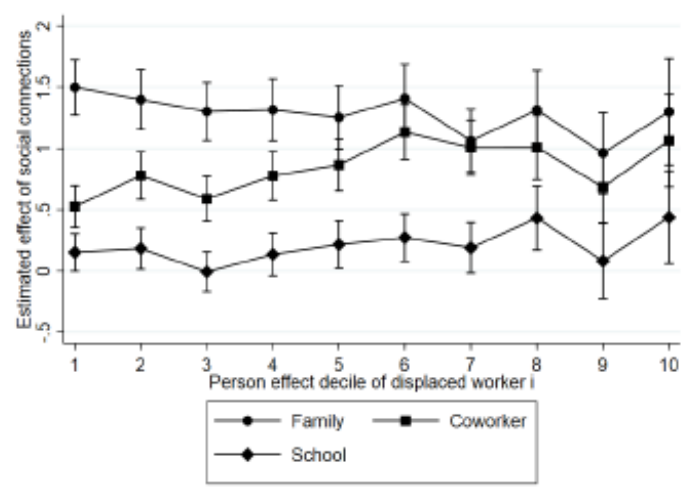

Figure 6: Individual fixed-effects estimates of the effect of social connections relative to current neighbors by $\mathrm{AKM}$ effect $\left(\theta_{i}\right)$ decile of displaced worker

Notes: The figure is based on the model in column (3) of Table 4, which includes individual and set of connected establishment and year fixed-effects. It shows the interactions with connection type and the AKM person effect decile. Current neighbors is the reference category. Standard errors are clustered on the potential hiring establishment-and-year level. All estimates are expressed in percentage points. 
(a) By AKM decile of displaced worker (i) for low, (b) By AKM decile of potential hiring establishmedium and high terciles of establishment $(k)$ effects ment $(k)$ for low, medium and high terciles of displaced worker $(i)$ person effects
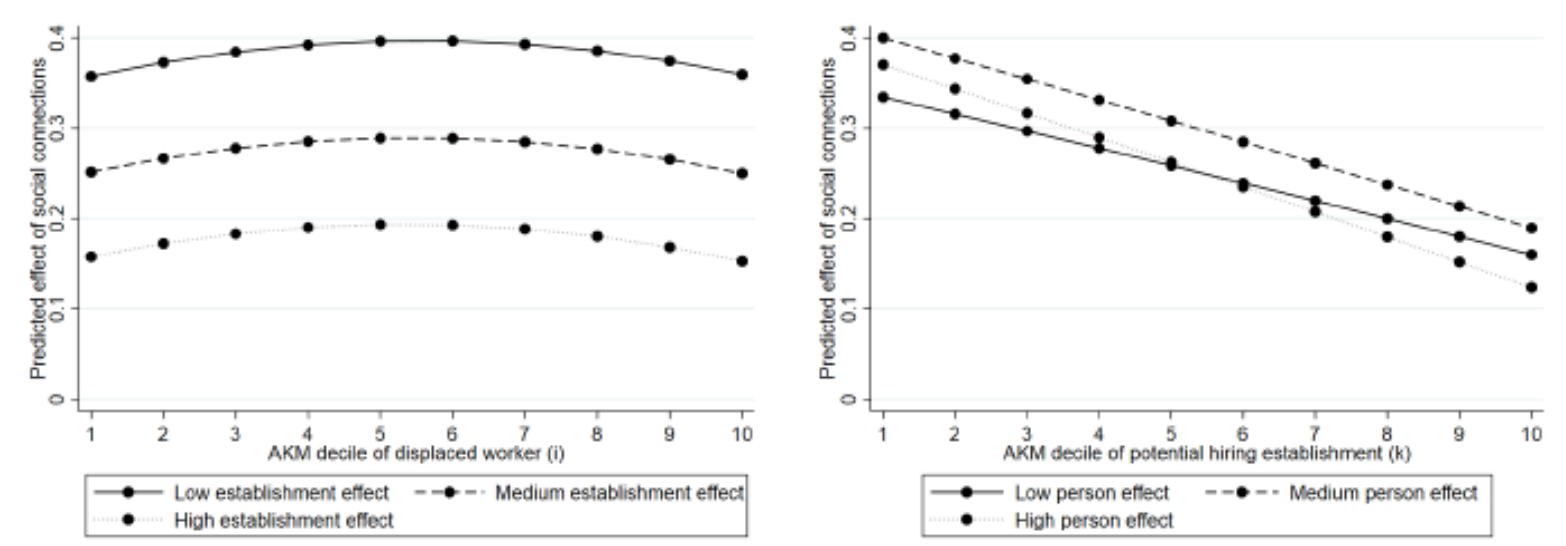

(c) By joint distribution of person (i) and establish- (d) Baseline hiring probabilities without connections, ment $(k)$ AKM deciles

by joint distribution of person $(i)$ and establishment $(k)$

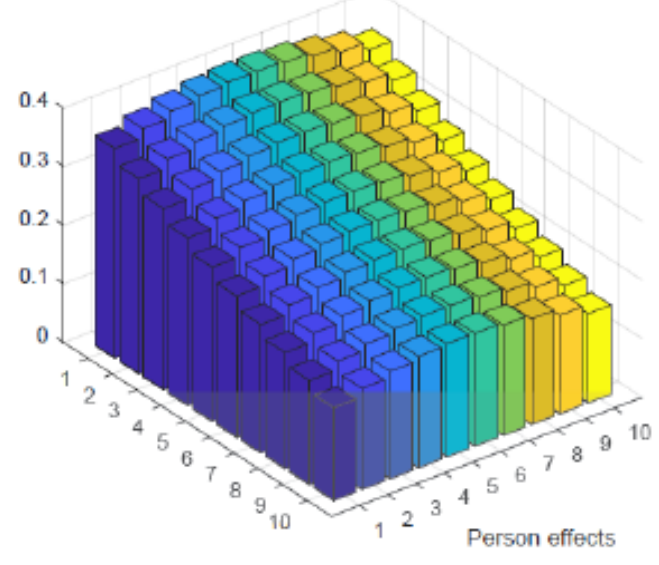

Establishment effects
AKM deciles

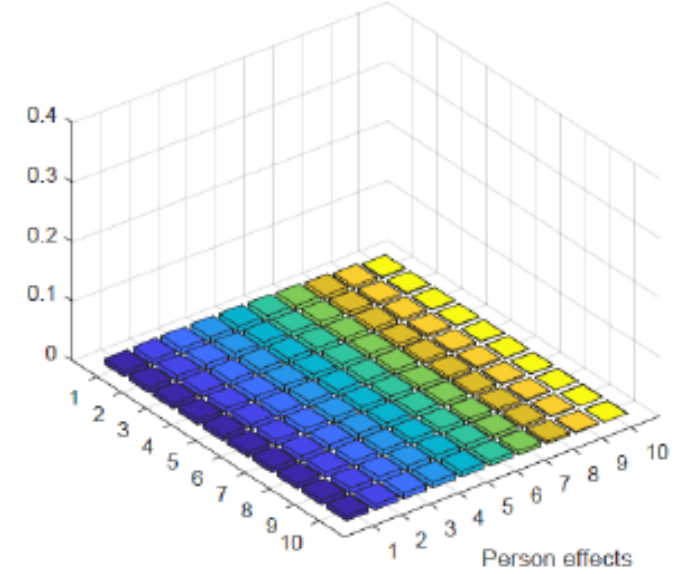

Establishment effects

Figure 7: Effects of social connections on hiring, by joint distribution of person and establishment effects Notes: The figures show the predicted hiring effect of social connections obtained from estimating equation (4), i.e., from interacting social connections with a second order polynomial of both the AKM person effect of the displaced and the establishment effect of the potential hiring establishment (in percentiles). All estimates are from the same regression. Panel a) and b) show slices of the $3 \mathrm{~d}$ graph of panel c). For underlying estimates and standard errors see the Appendix Table B.4. All estimates are expressed in percentage points.

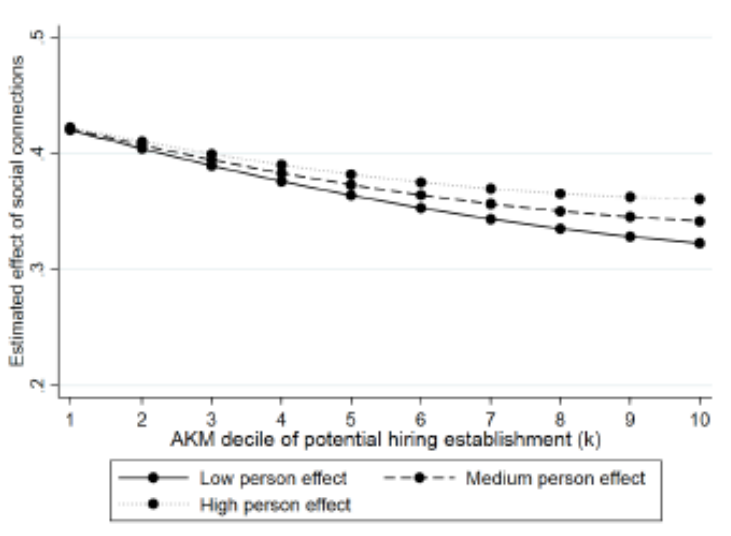

Figure 8: Within-worker identification estimates by potential hiring establishment deciles, for low-, medium-, and high-wage displaced workers.

Notes: The figure is based on the model of equation (6), which includes worker and set of connected establishments and year fixed-effects. It shows the interactions with a second order polynomial of the AKM effect of the potential hiring establishment and the interaction between the AKM person effect of the displaced and the establishment effect of the potential hiring establishment. Note that the baseline person effect of the displaced is absorbed by the (worker) fixed-effect. The interaction term between person and establishment effect is not significant. (see Appendix Table B.4). All estimates are expressed in percentage points. 


\section{Results}

Table 7: AKM person effect of new hire as a function of the AKM establishment effect of the hiring establishment and social connections

\begin{tabular}{|c|c|c|c|c|}
\hline & (1) & (2) & (3) & (4) \\
\hline & Coef. & Coef. & Coef. & Coef. \\
\hline \multicolumn{5}{|l|}{ Panel A: Hired displaced workers } \\
\hline Connected hire & $1.467(0.500)$ & $1.573(0.499)$ & $1.612(0.499)$ & \\
\hline Hiring establishment AKM-effect & & & & \\
\hline$\times$ Connected hire & $0.048(0.008)$ & $0.032(0.008)$ & $-0.027(0.009)$ & \\
\hline$\times$ Market hire & $0.079(0.003)$ & $0.064(0.003)$ & $0.008(0.005)$ & \\
\hline F-test: Interactions are equal ( $p$-val.) & 0.0002 & 0.0001 & 0.0000 & \\
\hline No of observations & 83,540 & 83,540 & 83,540 & \\
\hline R-squared & 0.264 & 0.267 & 0.269 & \\
\hline \multicolumn{5}{|l|}{ Panel B: All hires } \\
\hline Connected hire & $2.301(0.084)$ & $2.524(0.084)$ & $2.481(0.084)$ & $1.479(0.094)$ \\
\hline \multicolumn{5}{|l|}{ Hiring establishment AKM-effect } \\
\hline × Connected hire & $0.081(0.001)$ & $0.051(0.001)$ & $-0.009(0.001)$ & $-0.020(0.002)$ \\
\hline$\times$ Market hire & $0.116(0.000)$ & $0.088(0.001)$ & $0.029(0.001)$ & $-\quad-$ \\
\hline F-test: Interactions are equal ( $p$-val.) & 0.0000 & 0.0000 & 0.0000 & - \\
\hline Observations & $3,315,521$ & $3,315,521$ & $3,315,521$ & $3,315,521$ \\
\hline R-squared & 0.302 & 0.306 & 0.309 & 0.408 \\
\hline Year specific effects & Yes & Yes & Yes & Yes \\
\hline Origin establishment AKM-effects & No & Yes & Yes & Yes \\
\hline Hiring establishment fixed effects & No & No & No & Yes \\
\hline
\end{tabular}




\section{Results}

(a) All hires

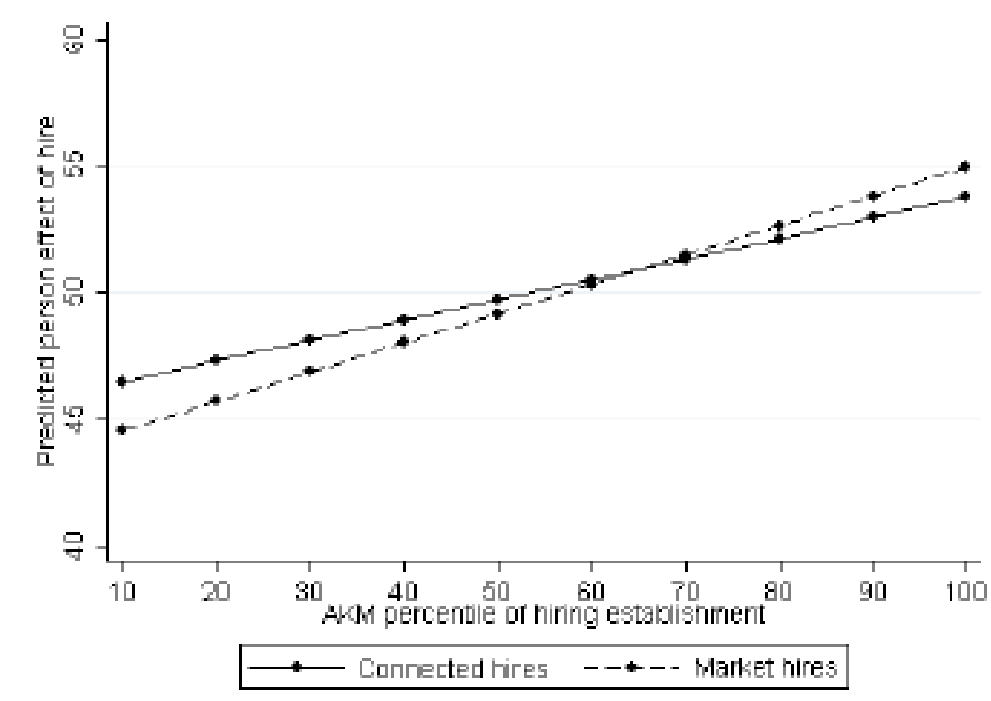

(b) Hired displaced workers

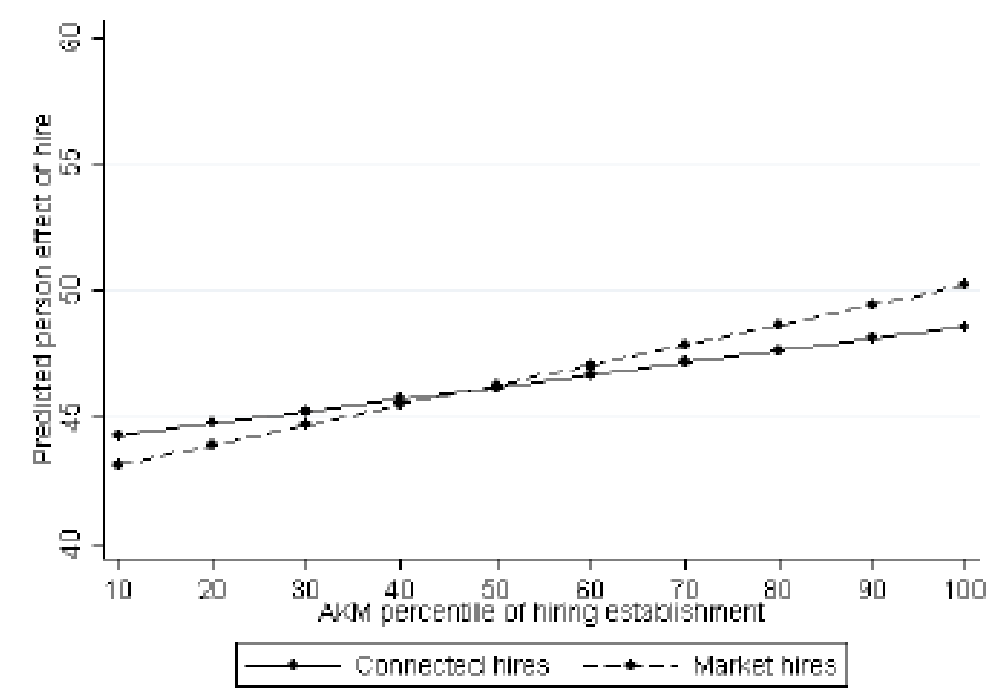

Figure 9: Predicted person effect of new hire as a function of hiring establishment effects and the use of social connections

Notes: The figure shows the predicted relationships between person effects of new hires, the hiring establishment effect and the hiring channel (connection/no connection). For estimates and standard errors see Table 7. We have added the mean person effect within each sample. 


\section{Validation analyses}

Table 8: The role of competing connections (of higher quality), by potential hiring establishment effects

\begin{tabular}{|c|c|c|c|c|c|c|}
\hline & \multicolumn{6}{|c|}{ Estimated AKM effects of (potential) hiring establishment } \\
\hline & \multicolumn{2}{|r|}{ Low $\psi_{k}$} & \multicolumn{2}{|c|}{ Medium $\psi_{k}$} & \multicolumn{2}{|c|}{ High $\psi_{k}$} \\
\hline & Coef. & (s.e.) & Coef. & (s.e.) & Coef. & (s.e.) \\
\hline \multicolumn{7}{|l|}{ Panel A } \\
\hline Any connection (C) & 0.2513 & $(0.0093)$ & 0.2127 & $(0.0069)$ & 0.1628 & $(0.0059)$ \\
\hline $\mathrm{C} \times$ Competing Connection $(\mathrm{CC})$ & -0.0691 & $(0.0185)$ & -0.1022 & $(0.0182)$ & -0.1301 & $(0.0191)$ \\
\hline Constant & 0.0164 & $(0.0005)$ & 0.0210 & $(0.0004)$ & 0.0149 & $(0.0003)$ \\
\hline No of fixed-effects & & 478,128 & & 684,111 & & 734,016 \\
\hline No of observations & & $9,496,877$ & & $13,182,356$ & & $13,747,457$ \\
\hline \multicolumn{7}{|l|}{ Panel $B$} \\
\hline Any connection (C) & 0.2604 & $(0.0098)$ & 0.2112 & $(0.0069)$ & 0.1562 & $(0.0059)$ \\
\hline $\mathrm{C} \times \mathrm{CC}$ & -0.0196 & $(0.0220)$ & -0.0568 & $(0.0213)$ & -0.0573 & $(0.0229)$ \\
\hline $\mathrm{C} \times$ Higer CC Quality & -0.1038 & $(0.0225)$ & -0.0699 & $(0.0162)$ & -0.0964 & $(0.0151)$ \\
\hline Constant & 0.0163 & $(0.0005)$ & 0.0210 & $(0.0004)$ & 0.0149 & $(0.0003)$ \\
\hline No of fixed-effects & & 478,128 & & 684,111 & & 734,016 \\
\hline No of observations & & $9,496,877$ & & $13,182,356$ & & $13,747,457$ \\
\hline \multicolumn{7}{|c|}{$\begin{array}{l}\text { Notes: The regressions are restricted to potential hiring establishments where no two (or more) employees had connections } \\
\text { to the same displaced worker. Observations with missing quality measures are accounted for missing variable indicators. All } \\
\text { estimates are expressed in percentage points, i.e., the coefficients are multiplied by } 100 \text {. All estimations include establishment- } \\
\text { pair(-and-year) fixed-effects. Competition and quality measures are demeaned (using the mean among those with a con- } \\
\text { nection). Standard errors are clustered on the potential hiring establishment-and-year level. "Competing Connection" is an } \\
\text { indicator taking the value one if some other displaced worker (in the same year) has a connection to the same establishment. } \\
\text { "Higher Competing Connection Quality" (HCCQ) is an indicator variable taking the value one if (some) Competing Connec- } \\
\text { tion is mediated by an intermediary worker with a higher estimated person effect than subject } i \text { 's intermediary worker (i.e., } \\
H C C Q_{i k}=I\left[\theta_{l(i, k)}>\theta_{l(k, i)} \text { for some } \tilde{i} \text { who is displaced in the same year as } i \text { with a connection to } k \text {.). }\right.\end{array}$} \\
\hline
\end{tabular}




\section{Validation analyses}

(a) Former co-workers

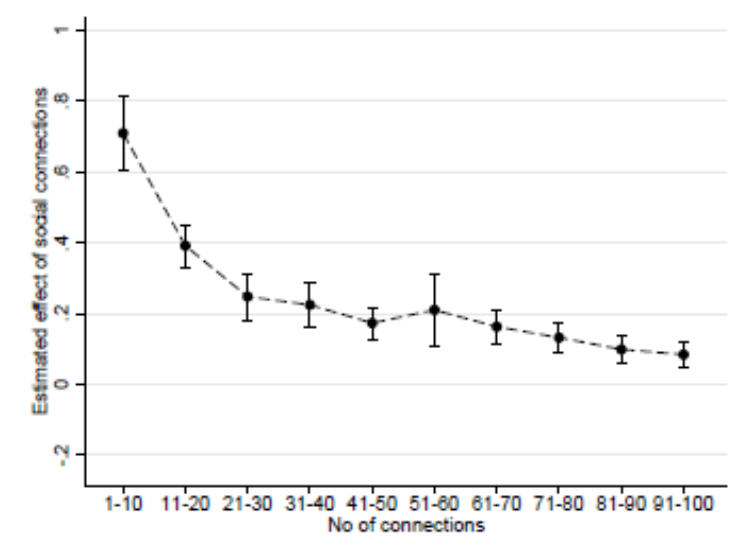

(c) Former classmates (university/college)

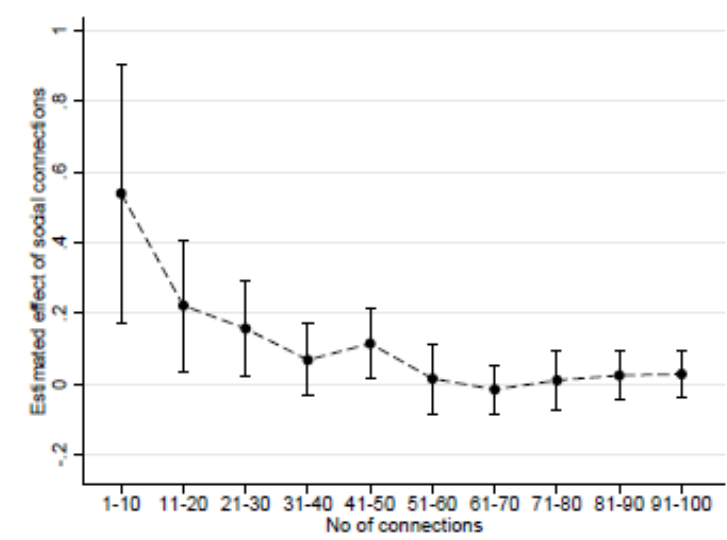

(b) Former classmates (high school)

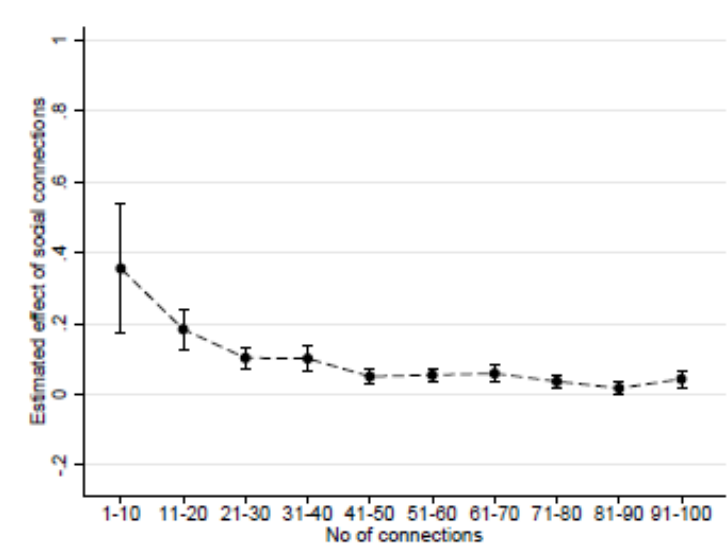

(d) Current neighbors

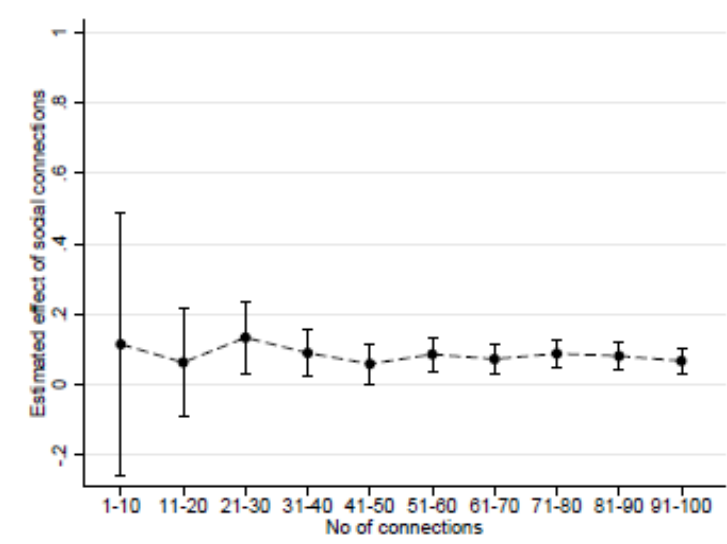

Figure 10: The estimated impact of a connection on the hiring probability, by the size of the particular network (i.e., the workplace, class, or neighborhood), with 95 percent confidence intervals, for former co-workers, former classmates (high school and college/university), and current neighbors

Notes: All estimates are obtained from the same estimation, where the indicator for the particular connection has been replaced by its interactions with the size of the particular network (10 categories). The estimates are expressed in percentage points, i.e., the coefficients are multiplied by 100. All estimations include establishment-pair(-and-year) fixed-effects. Standard errors are clustered on the potential hiring establishment-and-year level. 


\section{Validation analyses}

(a) Former co-workers

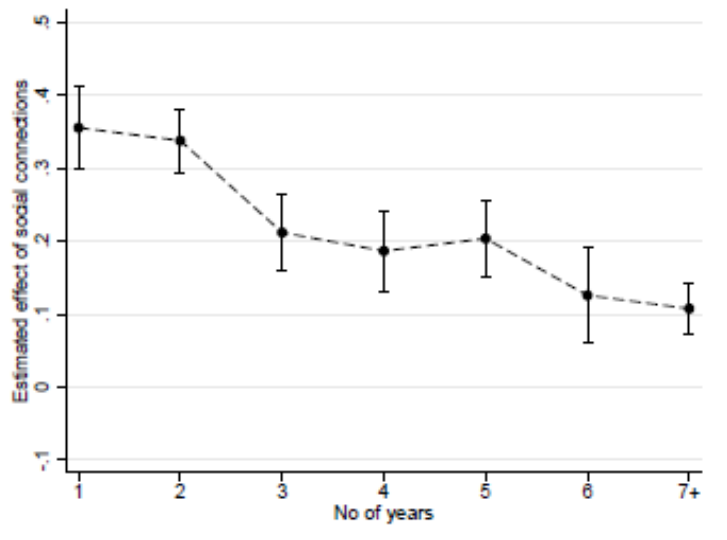

(b) Former classmates (high school)

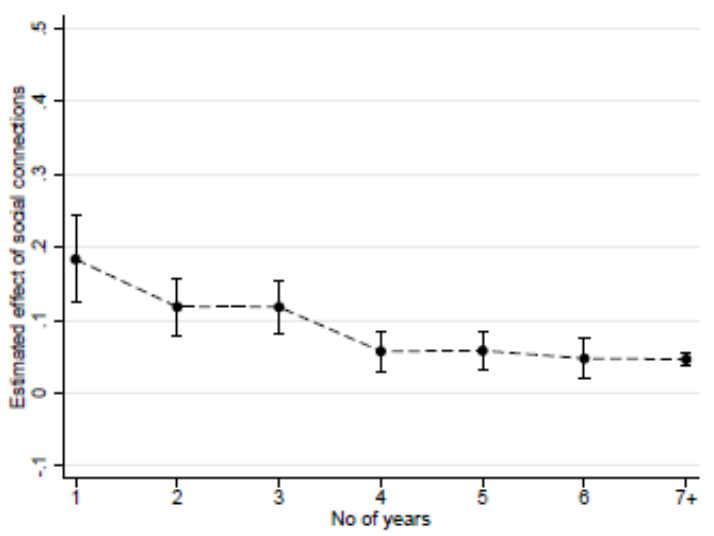

(c) Former classmates (university/college)

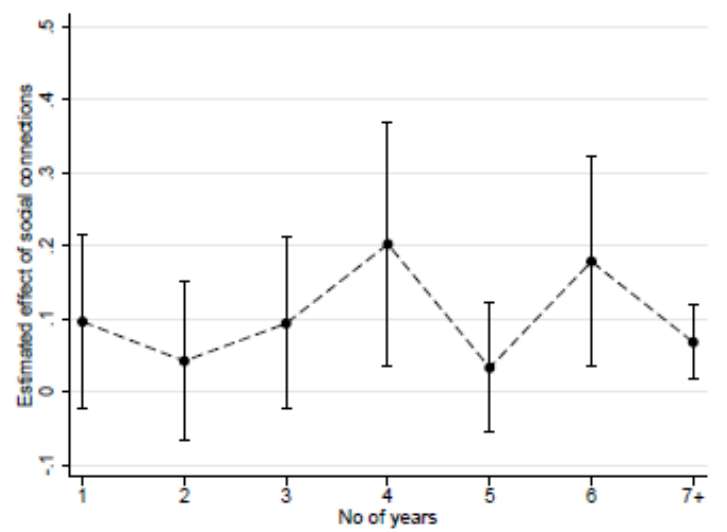

Figure 11: The estimated impact of a connection on the hiring probability, by time since interaction, with 95 percent confidence intervals, for former co-workers and former classmates (high school and college/university)

Notes: All estimates are obtained from the same estimation, where the indicator for the particular connection has been replaced by its interactions with time since interaction (7 categories). The estimates are expressed in percentage points, i.e., the coefficients are multiplied by 100. All estimations include establishment-pair(-and-year) fixed-effects. Standard errors are clustered on the potential hiring establishment-and-year level. 


\section{Validation analyses}

(a) Former co-workers

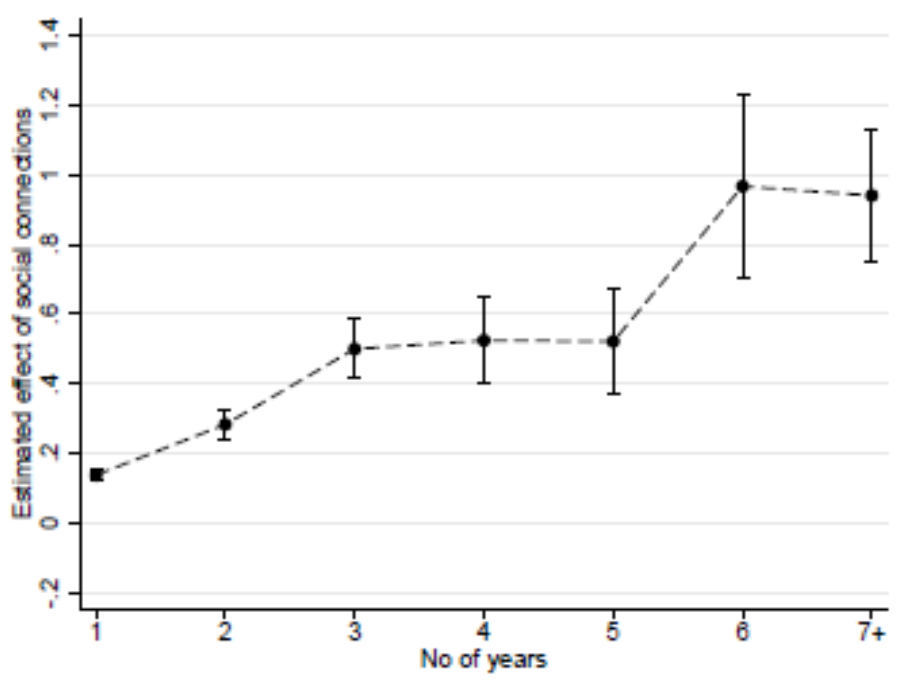

(b) Current neighbors

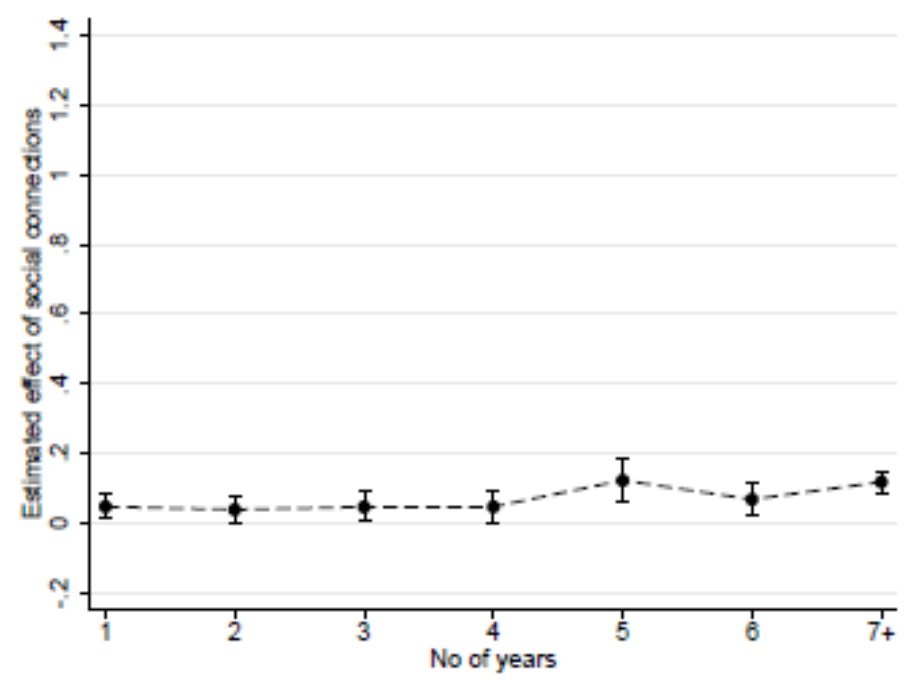

Figure 12: The estimated impact of a connection on the hiring probability, by interaction time, with 95 percent confidence intervals, for former co-workers and current neighbors

Notes: All estimates are obtained from the same estimation, where the indicator for the particular connection has been replaced by its interactions with interaction time (7 categories). The estimates are expressed in percentage points, i.e., the coefficients are multiplied by 100. All estimations include establishment-pair(-and-year) fixed-effects. Standard errors are clustered on the potential hiring establishment-and-year level. 


\section{Validation analyses}

Table 9: Post-hire outcomes

\begin{tabular}{|c|c|c|c|c|c|c|c|c|}
\hline & \multirow{2}{*}{\multicolumn{2}{|c|}{$\frac{\text { Outcomes after } 1 \text { year }}{\log (\text { Earnings })^{a}}$}} & \multicolumn{6}{|c|}{ Outcomes after 3 years } \\
\hline & & & \multicolumn{2}{|c|}{$\log (\text { Earnings })^{a}$} & \multicolumn{2}{|c|}{ Employed $^{b}$} & \multicolumn{2}{|c|}{ Job stability $^{c}$} \\
\hline & Coef. & (s.e.) & Coef. & (s.e.) & Coef. & (s.e.) & Coef. & (s.e.) \\
\hline \multicolumn{9}{|l|}{ Panel A } \\
\hline Any connection & 0.083 & $(0.013)$ & 0.175 & $(0.019)$ & 0.029 & $(0.004)$ & 0.128 & $(0.007)$ \\
\hline Constant & 11.043 & $(0.026)$ & 10.805 & $(0.027)$ & 0.747 & $(0.005)$ & 0.249 & $(0.005)$ \\
\hline \multicolumn{9}{|l|}{ Panel B } \\
\hline Family member & 0.002 & $(0.018)$ & 0.152 & $(0.027)$ & 0.028 & $(0.006)$ & 0.136 & $(0.008)$ \\
\hline Former co-worker & 0.137 & $(0.019)$ & 0.148 & $(0.031)$ & 0.020 & $(0.006)$ & 0.076 & $(0.011)$ \\
\hline Former classmate & 0.179 & $(0.029)$ & 0.201 & $(0.049)$ & 0.021 & $(0.010)$ & 0.158 & $(0.017)$ \\
\hline Current neighbor & 0.126 & $(0.037)$ & 0.197 & $(0.059)$ & 0.036 & $(0.013)$ & 0.152 & $(0.023)$ \\
\hline Constant & 11.043 & $(0.026)$ & 10.805 & $(0.027)$ & 0.747 & $(0.005)$ & 0.249 & $(0.005)$ \\
\hline No of fixed-effects & & 29,554 & & 29,554 & & 29,554 & & 29,554 \\
\hline No of observations & & 208,738 & & 208,738 & & 208,738 & & 208,738 \\
\hline
\end{tabular}

Notes: The estimation sample is all displaced workers who were employed in in November of year $t+1$. All estimations include closing establishment (-and-year) fixed-effects and controls for the workers' age, sex, education, and three years of pre-displacement employment, earnings, and employer history. Standard errors are clustered on the closing establishment (and-year) level.

${ }^{a}$ Earnings is defined as annual labor income and has been left censored at SEK 1,000.

${ }^{b}$ Employed is defined as being employed in November of year $t+3$.

${ }^{c}$ Job stability is defined as being employed at the same establishment in November of both year $t+1$ and $t+3$. 


\section{Conclusion}

- Social networks (Potential connections) are homophilous ... mostly those formed at work and at university which connect high-wage workers to high-wage employers

- For hiring, family networks matter most ...

... co-workers a bit less, neighbors, and classmates least

- Connections really matter:

- Repeated displacements

- The tighter social proximity, the larger the effect

- However, most of the effects of connections on hiring comes from low-wage employers, regardless of the connected worker

- Hence, low-wage employers are able to attract high-wage workers through social connections ...

Connected hires are less sorted than market hires 